\title{
Improvement of data quality in Seismic While Drilling
}

\author{
Tetsuro TSURU* and Toshiyuki YOKOTA " \\ *Frontier research program of subduction dynamics \\ Japan Marine Science and Technology Center (JAMSTEC) \\ 2-15 Natsushima-cho, Yokosuka, Japan \\ **Technology research center \\ Japan National Oil Corporation (JNOC) \\ 2-2 Hamada 1-chome, Mihama-ku, Chiba, Japan
}

\begin{abstract}
Alsotract
Seismic while drilling (SWD) is a seismic survey technology using a working drill-bit as an energy source. We can specify bit location on the existing seismic time section and can predict a drilling hazard ahead of the bit, 'while drilling', by using SWD technology. Vertical Seismic Profiling (VSP) also can be used for the same purpose. In comparison with VSP, advantages of SWD are its survey cost and quick availability of the survey result, such as T-D (Time-Depth) information. However, a serious disadvantage exists in the data quality due to contamination by noise generated from the working rig. Furthermore, there is a limitation to applicability on the SWD technology currently in use, when drilling with a PDC (Polycrystal-line Diamond Compact) bit or drilling in unconsolidated rocks. In this paper, we proposed a data acquisition method, a data processing method and a new energy source system for improving the quality of the SWD data. Efficacy of those methods and the system were demonstrated by field experiments.
\end{abstract}

\section{Introduction}

During the course of drilling a well, specifying a bit location on the existing seismic section and predicting a formation boundary below the bit are highly required for economic and safety reason. The SWD using the working drill bit as the energy source (e.g. Rector and Hardage, 1992; Ashida, 1997) is a seismic survey technology that can be used for this purpose. VSP (Vertical Seismic Profiling) also can be used for the same purpose at the well site. In comparison with VSP, advantages of SWD are its survey cost and quick availability of the survey result, such as T-D (Time-Depth) information. However, a serious disadvantage exists in the data quality due to contamination by noise generated from the working rig (hereinafter, rig noise), because the SWD survey is done while drilling. Furthermore, there is a limitation to applicability on the SWD technology currently in use, when drilling with a PDC (Polycrystalline Diamond Compact) bit or drilling in unconsolidated rocks.

To overcome the data quality reduction by the rig noise, Rector and Marion (1991) successfully improved a drill-bit signal by use of a pilot sensor at the top of the drill string, Miranda et al. (1996) optimized a pilot signal by the SeisBit system using several pilot sensors, Navile et al. (1994) directly obtained a drill-bit signal by the TRAFOR MWD system using a downhole sensor, Hardorsen et al. (1995) increased accuracy of both direct and reflection waves by a deconvolution filter calculated from the geophone-array data, and 
Kozawa and Tsuru (1998) predicted a formation boundary $800 \mathrm{~m}$ below the bit by an improved geophone-array deployment to eliminate the rig noise. Thus many authors have proposed the methods for improving the SWD data quality. However, efficacy of these methods were examined when drilling with a roller-cone bit in a consolidated-rock area. To expand the applicability of the SWD survey, Tsuru et al. (1998a) developed an artificial downhole energy source which oscillates with an acceleration amplitude of $9.8 \mathrm{~m} / \mathrm{sec}^{2}$ in the seismic band, which is higher than that of the working drill-bit.

In this paper, we summarize our data acquisition/processing methods to improve the data quality and a newly designed system, called Active SWD, to expand the applicability of the SWD survey.

\section{Data quality reduction by rig noise}

Contamination of seismic waves generated from the working rig strongly reduces data quality of the SWD record. Such waves are called rig noises and their main noise generators are considered to be a rig engine, a mud pump and a rotary table (Rector and Hardage, 1992). However, quantitative investigations on the characteristics of the rig noise are rarely reported.

We conducted the noise characteristics evaluation test at the actual drilling in the Kashiwazaki field test facility (Figure 1) of the Japan National Oil Corporation (JNOC). During the test, a bit was kept off bottom of the well so that no SWD signal was included in the records. Non-arrayed surface geophones were deployed near the well site and eastward from the well, as shown in Figure 1, for observation of the noise characteristics such as frequency and attenuation.

We obtained three kind of noise records in different rig-working conditions; (Test 1) only a draw works engine working, (Test 2) engines for a draw works and a mud pump, a mud pump and a mud screen working, (Test 3) a draw works engine and a rotary table working. The result shows that main rig noise generator is an engine and higher limit of the dominant frequency of the noise extend to about $35 \mathrm{~Hz}$ (Figure 2). Furthermore, the rig noise still has enough energy to be obviously observed at the far-offset receiver point $500 \mathrm{~m}$ from the well, as shown in Figure 3.

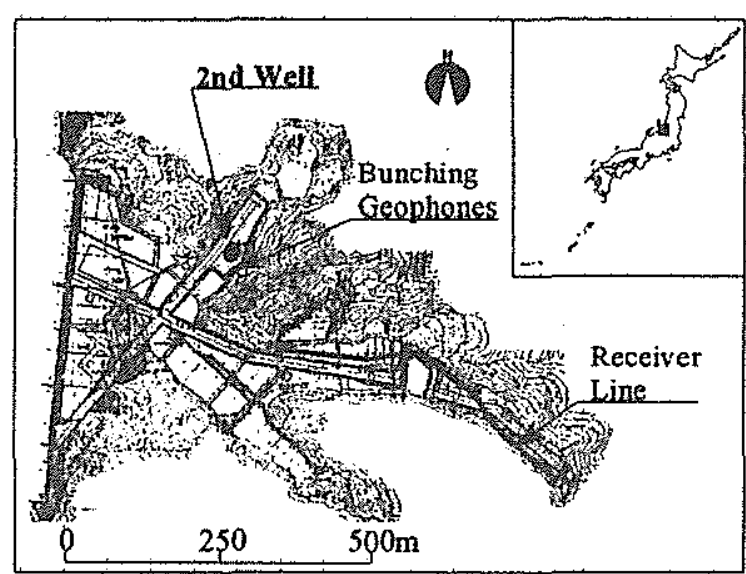

Figure1 Location map of noise characteristics evaluation test.

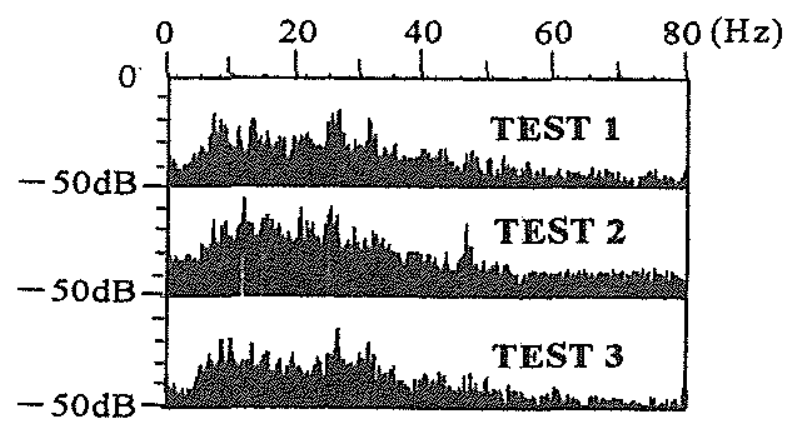

Figure2 Amplitude spectrums of rig noises in different drilling conditions.

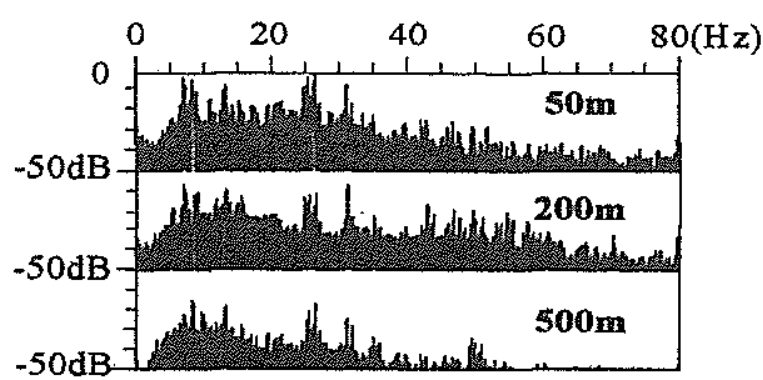

Figure 3 Amplitude spectrums of rig noises at different offset distances $(50 \mathrm{~m}, 200 \mathrm{~m}, 500 \mathrm{~m})$. 


\section{Field Experiment}

Based on the noise characteristics examination, data acquisition specification was improved in a surface geophone deployment, a pilot sensor type and so on (Table 1). The obtained multi-channel data were stacked at the data processing.

Table1 Specifications of data acquisition

\begin{tabular}{|l|l|}
\hline $\begin{array}{l}\text { Surface geophone } \\
\text { type }\end{array}$ & $\begin{array}{l}\text { F0=30 Hz, buried } 50 \mathrm{~cm} \\
\text { under the ground. }\end{array}$ \\
\hline $\begin{array}{l}\text { Surface geophone } \\
\text { deployment }\end{array}$ & $\begin{array}{l}500 \text { to } 1200 \mathrm{~m} \text { offset, } \\
100 \mathrm{~m} \times 100 \mathrm{~m} \text { cross } \\
\text { array }\end{array}$ \\
\hline Pilot sensor type & geophone, F0=30 Hz \\
\hline Controlled drilling & $\begin{array}{l}\text { WOB }=20 \text { tons, } \\
\mathrm{RPM}=40 \text { cycles/minute }\end{array}$ \\
\hline
\end{tabular}

The field experiment has demonstrated the efficacy of the improvement. The resulting $\mathrm{T}$ $D$ (Time to Depth) curve is well matched to that of the VSP which has conducted at the same well, as seen on Figure 4. A formation boundary $800 \mathrm{~m}$ below the bit can be recognized as a remarkable reflection on the SWD migrated section (Figure 5). Thus the SWD data quality was dominantly improved by eliminating the rig noises. However, we have not overcome, at that time, a limitation on the SWD applicability which concerns a PDC bit and unconsolidated rocks.

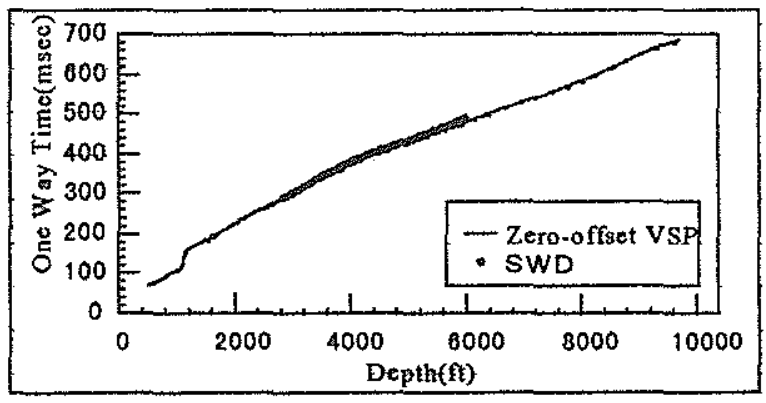

Figure4 T-D curve.

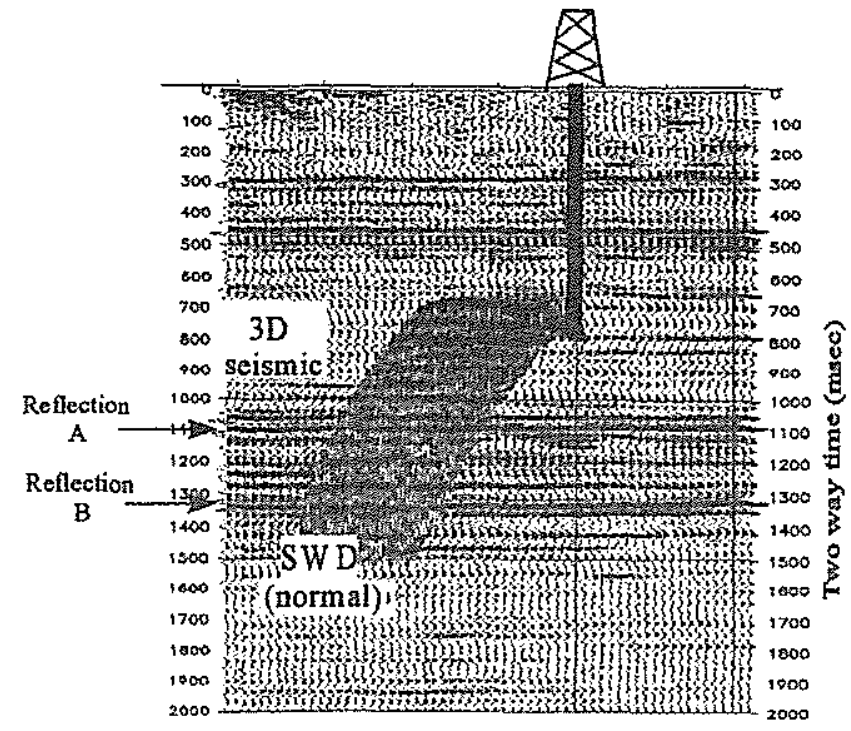

Figure 5 SWD subsurface image superimposed in the surface seismic section.

\section{Active SWD}

When drilling by a PDC bit or drilling in unconsolidated rock, applicability of the SWD survey is strongly limited because it is not easy to obtain the signals due to lack of seismic wave energy radiated from the bit. A new SWD system, called the Active SWD, using an artificial energy source is designed in order to overcome this limitation (Figure 6).

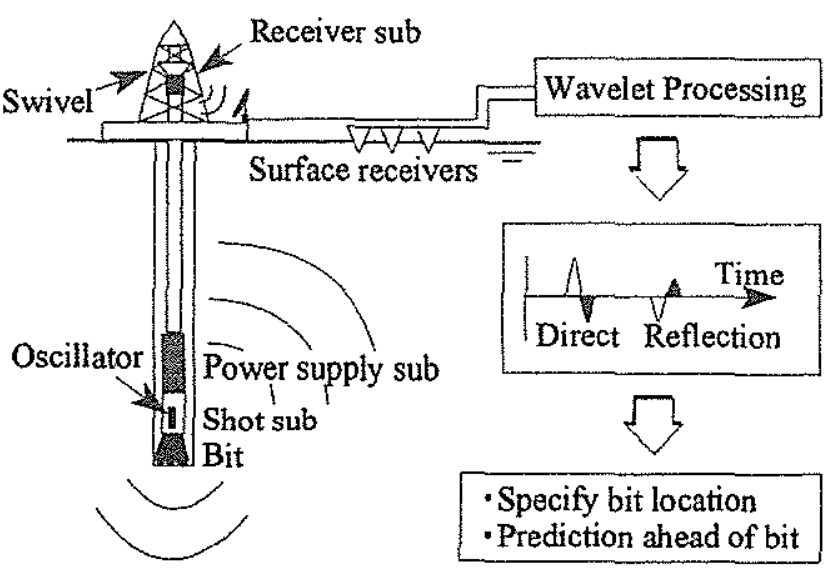

Figure6 Active SWD system. 
The artificial energy source can generate 9.8 $\mathrm{m} / \mathrm{sec}^{2}$ ( 1 G) of a seismic wave in an acceleration amplitude in the seismic band (Figure 7). This energy level is about two times higher than that of a bit signal from the roller-cone bit in case of drilling the consolidated rock.

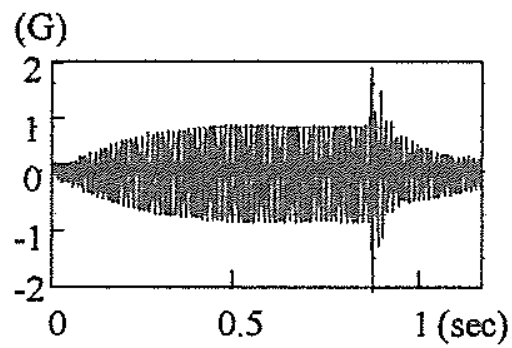

Figure 7 Source wavelet

\section{Conclusion}

We proposed a data acquisition method, a data processing method and a new energy source system for improving the quality of the SWD data. Efficacy of those methods and the system were demonstrated by field experiments.

\section{Acknowledgment}

I would like to express my sincere gratitude to Professor Yuzuru Ashida of Kyoto University for his advise and suggestion. I am greatly indebted to the following for progress in research : Mr. Takeshi Kozawa, Mr. Kenji Ota, Mr. Narikazu Uchiyama, Mr. Ryosuke Taniguchi, Mr. Kanji Matsuhashi and Mr. Nobutaka Nishikawa.

\section{References}

(1)Ashida, Y. (1997) : SWD, Butsuri-Tansa, $50,252-256$.

(2)Hardorsen, J., D. Miller and J. Walsh (1995): Walk-away VSP using drill noise as a source, Geophysics, 60, 978-997.

(3)Kozawa, T. and T. Tsuru (1998) : SWD experiment at Southwest Andrews oil fields, Butsuri-Tansa, 51, 127-140.

(4)Miranda, F., L. Aleotti, F. Abramo, F. Poletto, A. Craglietto, S. Persoglia and F. Rocca (1996) : Impact of the seismic 'While drilling' technique on exploration wells, First Break, vol.14, No.2, 55-68.

(5)Navile, C., P. C. Layotte, G. Pignard and J. Guesnon (1994): Well seismic - Application of the TRAFOR MWD system to drill-bit seismic profiling, 56th meeting, European Association of Exploration Geophysicists, Abstracts, G045.

(6)Rector, J. W. and B. P. Marion (1991) : The use of drill-bit energy as a downhole seismic source, Geophysics, 56, 628-634.

(7)Rector, J. W. and B. A. Hardage (1992) : Radiation pattern and seismic waves generated by a working roller-cone drill bit, Geophysics, 57, 1319-1333.

(8)Tsuru, T. and T. Kozawa (1998) : Noise characterization in SWD survey, ButsuriTansa, 51, 45-54.

(9)Tsuru, T., T. Kozawa, R. Taniguchi, K. Matsuhashi and N. Nishikawa (1998) : Trial to Active SWD using artificial energy source -Use of monochromatic source wavelet-, Butsuri-Tansa, 51, 117-126. 